\title{
Development of Paper Biosensor for the Detection of Phenol from Industrial Effluents Using Bioconjugate of Tyr-AuNps Mediated by Novel Isolate Streptomyces tuirus DBZ39
}

\author{
Bi Bi Zainab Mazhari, ${ }^{1}$ Dayanand Agsar, ${ }^{1}$ and M. V. N. Ambika Prasad ${ }^{2}$ \\ ${ }^{1}$ A-DBT Research Laboratory, Department of Microbiology, Gulbarga University, Kalaburagi, Karnataka 585 106, India \\ ${ }^{2}$ Department of Materials Science, Gulbarga University, Kalaburagi, Karnataka 585 106, India
}

Correspondence should be addressed to Bi Bi Zainab Mazhari; mbzainab@gmail.com

Received 13 October 2016; Revised 14 January 2017; Accepted 24 January 2017; Published 26 April 2017

Academic Editor: Maria D. King

Copyright (C) 2017 Bi Bi Zainab Mazhari et al. This is an open access article distributed under the Creative Commons Attribution License, which permits unrestricted use, distribution, and reproduction in any medium, provided the original work is properly cited.

\begin{abstract}
Paper biosensor was developed using Tyr-AuNps bioconjugate produced by Streptomyces for the detection of phenol from the effluent of wine, paper, and plastic industries. Among three filter papers assessed, Whatman number 2 filter paper was proved to be the best paper base for the development of biosensor. Tyrosinase and gold nanoparticles being produced by a single novel isolate Streptomyces tuirus DBZ39 proved to be efficient bioconjugate for the detection of phenol constituents, due to its biocompatibility. The substrate specific catalytic activity of the tyrosinase and unique Surface Plasmon Resonance attribute of gold nanoparticles are the cause for efficient detection of phenol constituents from the effluent of wine, paper, and plastic industries in 3 min. The different types and quantity of phenolic constituents in various industrial effluents, such as phenol in wine, dopamine in paper, and catechol in plastic effluents, were accurately detected by the bioconjugate. The efficacy of tyrosinase in the detection of phenol constituents was expected to be enhanced by the gold nanoparticles because of their electron, optical, and magnetic properties. This novel paper strip biosensor could be cost-effective and efficient means of future devices for the detection of phenolic pollutants from any environmental samples.
\end{abstract}

\section{Introduction}

Phenols of anthropogenic origin exist in the environment due to the activity of the chemical, petrol, tinctorial, or pharmaceutical industries. They are among the most abundant organic impurities penetrating into the aquatic environment as a result of their use in a large number of processes, including petroleum and paper industry and synthesis of plastics [1]. Phenols are widely used organic compounds in existence and are a basic structural unit for a variety of synthetic organic compounds including agricultural chemicals and pesticides. Toxicity of phenol is related to hydrophobicity of the individual compound and formation of free radicals [2]. Because most phenolic compounds exhibit a high degree of toxicity, they have been included in the list of high priority pollutants by the US Environmental
Protection Agency (EPA) and several other countries [3]. The European Union has set the maximum total and individual phenol permitted concentrations in water used for human consumption at 0.5 and $0.1 \mathrm{mg} / \mathrm{L}$, respectively [4]. To evaluate the risks which these compounds pose, a rapid and reliable process for their determination is therefore necessary. Several physicochemical and biological methods are in practice to monitor the phenol pollutants in water and soil. Many of the available advanced physicochemical techniques are highly sensitive but time-consuming and expensive and demand trained personnel for on-site or in-filed analysis [5]. The physicochemical methods, such as 4-AAP and FCR, are based on the phenols providing an intense red color development of the pyrazolones group, with maximum absorption in the wavelength of $510 \mathrm{~nm}$. As the reaction is an official and wellestablished method for phenolic compound determinations 
in water samples, it has been used for comparison purposes in the development of new methods. Many times, the method is tedious and time-consuming [6]. Biological processes are gaining importance over physicochemical processes as biological systems are more effective and the end products formed are nontoxic [7].

Bioconjugation is an important field of research resulting in the formulation of bioconjugates for varied applications. Conjugates of enzymes and nanoparticles are increasingly important in a wide range of applications including bioanalysis, imaging, and nanomedicine. Enzymes are biological catalysts that increase the rate of chemical reactions. Among enzyme sensors, tyrosinase enzyme proved to be very promising for the detection of phenolic compounds because of their high specificity of their substrates [8]. Tyrosinase (monophenol dihydroxyphenyl alanine; EC 1.14.18.1) is a copper containing metallo enzyme which catalyzes the oxidation of phenols, the ortho hydroxylation of monophenols to Odiphenols (monophenolase activity), and the oxidation of $\mathrm{O}$ quinones (diphenolase activity). Tyrosinase is also used as indicator for the portability of water by analyzing a phenolic compound released from coliforms in water [9], and as probe to sense the level of phenol constituents in media during large scale/industrial fermentation [10]. Nanoparticles are frequently employed to aid the detection of environmental pollutants as analytical sensor. These applications take advantage of the unique features of nanoparticles such as their large surface areas and their unique photochemical, electronic, or magnetic properties. The application of nanomaterials and nanotechnology in biosensors was reviewed and many novel nanomaterials with unique properties are increasingly being exploited to apply for biosensor, improving the property of biosensor and making them have higher selectivity and sensitivity, less response time, and lower detective limitation [11]. Gold nanoparticles are of great interest due to their fascinating optical properties and their promising applications [12]. The conjugation of enzymes with gold nanoparticles can lead to the retention or even to an increase of their biological stability/activity [13]. Enzyme-nanoparticles conjugates that take advantage of the catalytic activity of bound enzymes have been reported for bioanalytical and biotechnological applications [14].

A new type of paper based bioassay was developed for the colorimetric detection of phenolic compounds including phenol, bisphenol A, catechol, and cresols present in tap water and river water samples [15]. The sensor was based on layer by layer assembly approach on filter paper by physically trapping the mushroom tyrosinase in these layers. The senor response is quantified as a color change resulting from the specific binding of the enzymatically generated quinone on the paper. This assay has the advantage of rapidity and simplicity over other detection methods without need of sophisticated instrumentation and trained personnel. Enzyme biosensor based on tyrosinase for the detection of phenol compounds has been attracting great interest for fast and simple detection of pesticides [16-19] or phenol compounds in food [20] too. In the present investigation, it was aimed at developing paper biosensor for the detection of phenol constituents using bioconjugate of tyrosinase and gold nanoparticles produced by a novel strain of Streptomyces. Further, qualitative and quantitative determination of different types of phenols from the effluent of wine, paper, and plastic industries was reported.

\section{Materials and Methods}

2.1. Molecular Characterization of Streptomyces DBZ39. The potential strain of Streptomyces DBZ39 isolated earlier [21] was characterized by $16 \mathrm{~S}$ rRNA analysis [22]. The genomic DNA of the isolate was extracted and purified [23] DNA was subjected for PCR amplification. The purified PCR amplicons were sequenced using the gene specific sequencing universal standard primers [24] and 16S rRNA gene sequence was obtained. Using the sequence, phylogenetic tree was constructed following NCBI BLAST Search [25] to understand closest relatives.

\subsection{Tyrosinase and Gold Nanoparticles from Streptomyces} tuirus DBZ39. Extracellular tyrosinase produced earlier [21] was used for the preparation of bioconjugate. It was produced under submerged bioprocess by Streptomyces tuirus DBZ39, on laboratory scale, in $100 \mathrm{~mL}$ tyrosine broth containing tyrosine $0.5 \%$, beef extract $0.3 \%$, and gelatin $0.5 \%$ over a period of $120 \mathrm{~h} \mathrm{[26].} \mathrm{Partially} \mathrm{purified} \mathrm{tyrosinase} \mathrm{[21]} \mathrm{was}$ used to prepare the bioconjugate.

Extracellular gold nanoparticles with an average size of $15 \mathrm{~nm}$ synthesized earlier [21] in an optimized bioprocess by Streptomyces tuirus DBZ39, as per the standard protocol [27], were employed for the preparation of bioconjugate. A loop full of three-day-old test culture was inoculated into starch casein broth individually and incubated at $35^{\circ} \mathrm{C}$ for 5 days on shaker (200 rpm). After the incubation, the broth culture was centrifuged at $8000 \mathrm{rpm}$ for $20 \mathrm{~min}$ at $20^{\circ} \mathrm{C}$. The biomass obtained was washed 2-3 times with sterile distilled water, suspended in aurium chloride solution $(1 \mathrm{mM})$ and incubated at $40^{\circ} \mathrm{C}$ on shaker $(200 \mathrm{rpm})$ for three days. Extracellular gold nanoparticles synthesized in the solution were confirmed and characterized by visual observation and UV-vis absorption spectrum at $500-550 \mathrm{~nm}$.

2.3. Preparation of Bioconjugate. Bioconjugate of tyrosinase and gold nanoparticles from Streptomyces tuirus DBZ39 was prepared [21] by following the flocculation assay method [28]. $1: 39$ ratio of tyrosinase and gold nanoparticles was prepared and mixed in $10 \mathrm{mM}$ sodium bicarbonate solution and stored in dark for $40 \mathrm{~min}$. $200 \mu \mathrm{L}$ of $2 \mathrm{M} \mathrm{NaCl}$ was added to the mixture and again incubated in dark for $20 \mathrm{~min}$. Salt solution was replaced with $50 \mu \mathrm{l}$ of water in a reference sample, as control. The UV-vis absorbance of incubated mixture (1:39) was measured between 400 and $800 \mathrm{~nm}$. The characterization of bioconjugate of tyrosinase-gold nanoparticles was carried out by Dynamic Light Scattering (DLS) at Malvern Laboratory, Bangalore. The hydrodynamic radius of bioconjugate, revealing the surface morphology of tyrosinase-gold nanoparticles, was determined by subjecting bioconjugate with the flocculation ratio of $1: 39$ for DLS analysis.

2.4. Construction of Paper Biosensor. Normal, Whatman 1 and 2 filter papers were used as base or platform for the 

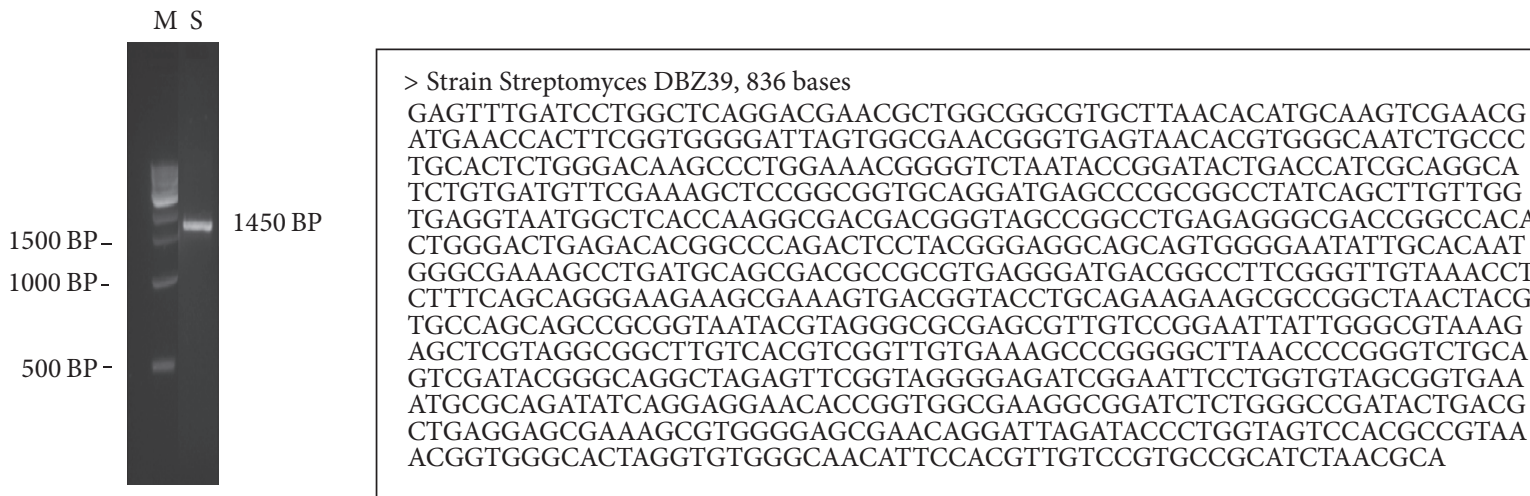

FIGURE 1: Genomic DNA and nucleotide sequence (partial-836 bases) of 16S rRNA gene of Streptomyces DBZ39.

construction of paper biosensor, following the standard modified procedure [29]. The multilayers of chitosan, TyrAuNps bioconjugate, and alginate were placed on the paper in sequence, one over another. The paper was first soaked in 1.5\% Sodium Tri-penta Phosphate (NaTPP) for $10 \mathrm{~min}$ and air dried for $30 \mathrm{~min}$. Three layers of $10 \mu \mathrm{L}$ chitosan followed by five layers of $200 \mu \mathrm{L}$ bioconjugate, two layers of $6 \mu \mathrm{L}$ alginate, and two layers of $20 \mu \mathrm{L}$ of 4 -AAP were placed on air-dried paper and allowed to be adsorbed. Thus constructed large paper biosensors were further air-dried for $45 \mathrm{~min}$, cut into strips of adequate size, and stored at $4^{\circ} \mathrm{C}$ for further use.

2.5. Detection of Phenol by Paper Biosensor. The phenol content of wine, paper, and plastic industrial effluents was detected by paper biosensors as per the prescribed method [30]. $25 \mu \mathrm{L}$ of effluent samples was placed separately on different paper biosensors and change in color was observed at different time interval ( 0 to $10 \mathrm{~min}$, at the interval of every minute). A sample of distilled water was used as control and the color of analytical grade phenol was considered as standard for comparison. The color developed in the effluent samples was determined by UV-vis absorption spectra and compared with standard chemical methods of 4-Amino Antipyrine (AAP) [31] and Folin-Ciocalteau Reagent (FCR) assays [32].

\section{Results and Discussion}

3.1. Novel Strain of Streptomyces. Actinomycetes are analyzed at various levels to gain information suitable for constructing data bases and effecting identification. Obviously, the highest level is the genome and its direct expression as RNA. Sequence analysis of various genes provides a stable classification and accurate identification, which has become the cornerstone of modern phylogenetic taxonomy. The regions of $16 \mathrm{~S}$ rRNA genes are highly variable and differ significantly between species, whereas other areas are more conserved and suitable for identification at the generic level [33]. This technique is the forerunner of molecular analysis and that has now been followed for bacterial identification.

Molecular characterization of an efficient and novel isolate Streptomyces DBZ39 was carried out by $16 \mathrm{~S}$ rRNA analysis. Agarose gel image (Figure 1) captured in BIO-RAD GelDocXR gel documentation system illustrates a purified $16 S$ rRNA gene after PCR amplification of genomic DNA. The size of 1450 bp of $16 \mathrm{~S}$ rRNA gene was revealed on comparison with $1 \mathrm{~kb}$ DNA marker. The partial sequence (in FASTA format) of 16S rRNA gene (Figure 1) includes 836 nucleotide bases. This $16 \mathrm{~S}$ rRNA gene sequence has been submitted to the Gene Bank database (accession number KP100263). The phylogenetic tree (Figure 2) obtained by Neighbor-Joining [34] analysis of $16 \mathrm{~S}$ rRNA gene sequence, showing the systematic position of strain Streptomyces DBZ39, among its phylogenetic neighbors was analyzed. DNA relatedness of two organisms was proved to be suitable for the investigation of relationships between closely related taxa [35]. Strains belonging to the same species will generally have greater than $70 \%$ DNA-DNA relatedness. Thus, the phylogenetic dendogram of Streptomyces DBZ39 disclosing 99.63\% similarity with Streptomyces tuirus reveals its identity as Streptomyces tuirus DBZ39. Rarely, either an organism produces two biomolecules or two molecules produced by a single organism are being explored together for the analysis of chemical pollutant from the nature. Generally, combination of a molecule from the biological source and another from chemical source has been employed for the preparation of a bioconjugate. However, biocompatibility of a bioconjugate in the process of sensing a pollutant would be very high, only if both the molecules are obtained from the single organism. In the present investigation, single organism Streptomyces tuirus DBZ39 is physiologically able to synthesize both tyrosinase and gold nanoparticles, for the preparation of a bioconjugate, which is novel and striking feature of these organisms.

3.2. Development of Paper Biosensor. A dry form of paper biosensor was developed with an aim to detect phenol by utilizing the effective properties of bioconjugate of Tyr-AuNps mediated by Streptomyces tuirus DBZ39. Dynamic Light Scattering (DLS) analysis of tyrosinase-gold nanoparticles bioconjugate at 1:39 flocculation ratio reveals the cohesion and adhesion of tyrosinase molecules on the surface of gold nanoparticles (Figures 3(a) and 3(b)). The maximum peak (Figure 3(a)) at $109.5 \mathrm{~nm}$ indicates the increased size of gold nanoparticles, when compared to 27 to $56 \mathrm{~nm}$ size 


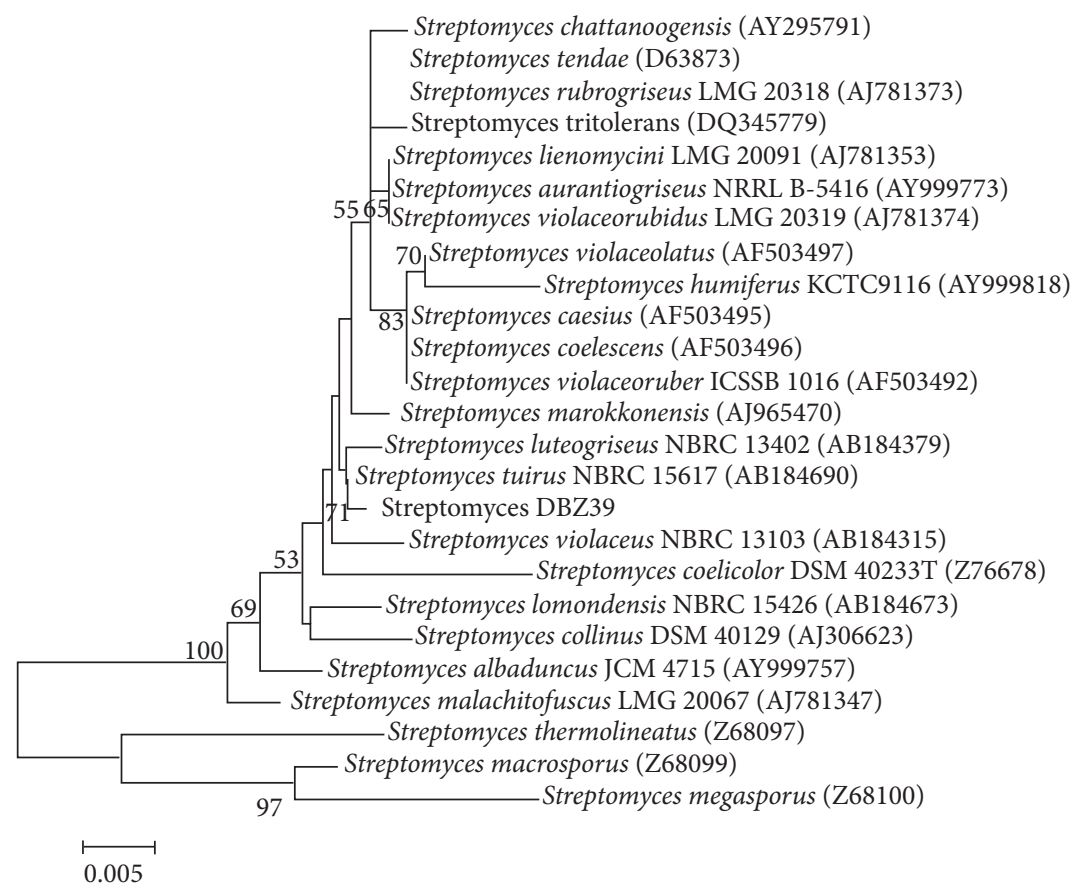

FIGURE 2: Phylogenetic tree showing systematic position of Streptomyces DBZ39.

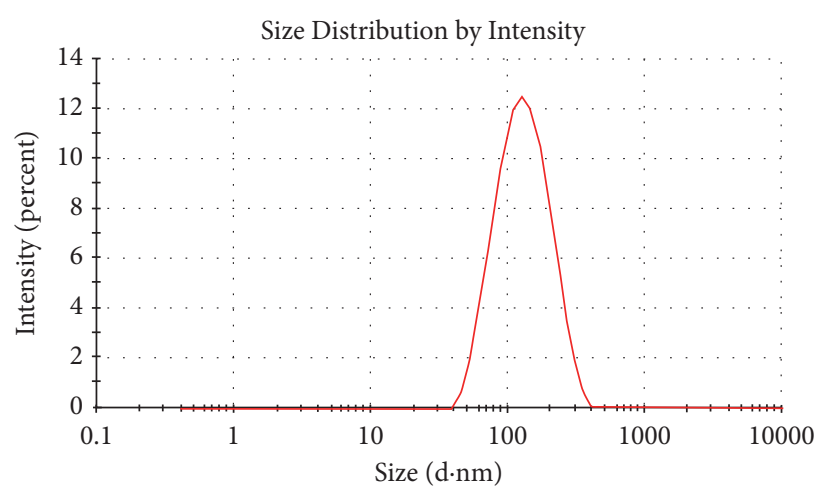

(a)

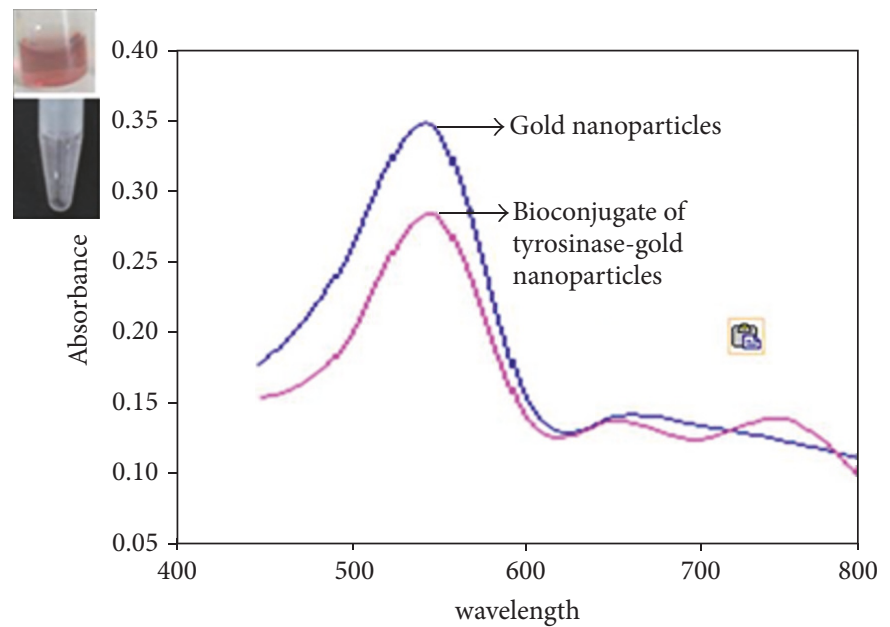

(b)

FIGURE 3: Dynamic light scattering peak indicating conjugation of tyrosinase and gold nanoparticles (a) UV-Vis spectra of tyrosinase and gold nanoparticles before and after conjugation.

of the gold nanoparticles used initially for the development of bioconjugate. Adsorption of NaTPP onto paper facilitated rapid ionic cross-linking and stabilization of chitosan onto the solid platform. The chitosan and bioconjugate of TyrAuNps of Streptomyces were immobilized onto the filter papers which include normal, Whatman 1 and 2 filter papers of different quality to construct an integrated, reagentlesssensing platform. Chitosan used previously as a coating material and an additive for cellulosic materials $[36,37]$ has been known to facilitate strong adsorption of biomolecules [38].
Functionalization of paper with chitosan improved the strength of paper [37], morphology, moisture barrier [39], and mechanical and optical properties [40]. Due to their surface charges and structural similarities, cellulose and chitosan interact strongly through electrostatic adsorption and hydrogen bonding which facilitate strong attachment of chitosan onto cellulosic paper $[37,38]$. This approach provided a biocompatible environment for the bioconjugate of Tyr-AuNps and enhanced protein adsorption through electrostatic binding, thus stabilizing the bioconjugate of Tyr-AuNps. Surface 
TABLE 1: Detection of phenol from industrial effluents by normal filter paper biosensor.

\begin{tabular}{lccc}
\hline \multirow{2}{*}{ Time intervals (min) } & \multicolumn{3}{c}{ Degree of phenol detection } \\
& $\begin{array}{c}\text { Winery } \\
\text { effluent }\end{array}$ & Paper effluent & $\begin{array}{c}\text { Plastic } \\
\text { effluent }\end{array}$ \\
\hline 0 & - & - & - \\
1 & - & - & - \\
2 & - & - & - \\
3 & - & - & - \\
4 & + & + & + \\
5 & +++ & ++ & ++ \\
\hline$-:$ no detection; +: poor detection; ++: & moderate detection; +++: good \\
detection.
\end{tabular}

Plasmon Resonance (SPR) of Gold nanoparticles is relatively more compatible to bind with tyrosinase and facilitates efficient detection of phenol constituents. Smaller size gold nanoparticles allow more freedom in the orientation for the anchored protein molecules and hence maximize the utilization of their bioactive sites [41]. Thus bioconjugate of tyrosinase and gold nanoparticles has been an efficient biosensor on Whatman 2 paper for the detection of phenol constituents.

Filter papers reveal different applications based on their various properties such as porosity, particle retention, wet strength, flow rate, compatibility, and efficiency. Even a small piece of filter paper has been known to absorb a significant volume of liquid. Whatman qualitative filter paper, grade 2 (8 micron), is slightly more retentive than grade 1 with a corresponding increase in filtration time and also more absorbent. In addition to general filtration in the $8 \mu \mathrm{m}$ particle size range, the extra absorbency was an added advantage and capable of retaining the fine precipitates encountered in chemical analysis. Whatman 2 filter paper was also used in quantitative air pollution analysis as a paper tape for impregnation when determining gaseous compounds at high flow rates.

3.3. Detection of Phenol by Paper Biosensor. In view of potential application of paper biosensor, experiments were performed to detect the phenol from the effluent of wine, paper, and plastic industries. The detection of phenol contents by the paper biosensors from the effluents of wine, paper, and plastic industries was recorded at different time intervals (Tables 1 , 2 , and 3). Table 1 depicts the poor (+) detection of phenol at $4 \mathrm{~min}$ by normal filter paper biosensor, whereas Table 2 shows the moderate $(++)$ detection of phenol from different industrial effluents at $4 \mathrm{~min}$ by Whatman 1 paper biosensor. Good $(+++)$ detection of phenol from different industrial effluents was recorded (Table 3 ) at 3 min by Whatman 2 paper biosensor. The various physicochemical properties of filter papers might be responsible for the detection of phenol contents at different levels. After placing the sample on paper biosensor, the phenols present in the effluents were oxidized by bioconjugate and produce quinone. 4-AAP present in the paper sensor react with the quinone and convert it into a colored adduct, which was visualized as a spot on the paper at different time intervals (0 to $10 \mathrm{~min}$ ).
TABLE 2: Detection of phenol from industrial effluents by Whatman 1 filter paper biosensor.

\begin{tabular}{lccc}
\hline \multirow{2}{*}{ Time intervals (min) } & \multicolumn{3}{c}{ Degree of phenol detection } \\
& $\begin{array}{c}\text { Winery } \\
\text { effluent }\end{array}$ & Paper effluent & $\begin{array}{r}\text { Plastic } \\
\text { effluent }\end{array}$ \\
\hline 0 & - & - & - \\
1 & - & - & - \\
2 & - & - & - \\
3 & - & - & - \\
4 & ++ & ++ & ++ \\
5 & +++ & ++ & ++ \\
\hline$-:$ no detection; +: poor detection; ++: & moderate detection; +++: good \\
detection. &
\end{tabular}

TABLE 3: Detection of phenol from industrial effluents by Whatman 2 paper biosensor.

\begin{tabular}{lccc}
\hline & \multicolumn{3}{c}{ Degree of phenol detection } \\
Time interval (min) & $\begin{array}{l}\text { Winery } \\
\text { effluent }\end{array}$ & Paper effluent & $\begin{array}{c}\text { Plastic } \\
\text { effluent }\end{array}$ \\
\hline 0 & - & - & - \\
1 & - & - & - \\
2 & + & - & - \\
3 & +++ & ++ & ++ \\
4 & +++ & ++ & ++ \\
5 & ++ & ++ & ++ \\
\hline$-:$ no detection; +: poor detection; ++: moderate detection; +++: good \\
detection.
\end{tabular}

The change of the color on the spots of paper biosensor was quite distinct (Figure 4), when compared to the control and a standard phenol. Different colors have been formed depending on the type of the phenol constituents present in the effluent. Appearance of reddish-brown color in the effluent of wine (Figure 4(a)) indicates presence of phenol, dark-brown color in effluent of paper (Figure 4(b)) indicates presence of dopamine, and orange color in effluent of plastic (Figure 4(c)) indicates presence of catechol. After 3 mins, no further color change was observed, which discloses that phenol contents could be detected in $3 \mathrm{~min}$. The development of color on the paper biosensor was first recorded by visual observation and then compared with the standard phenol as control (Figures 4(a), 4(b), and 4(c)). The intensity of color developed in the treated effluent would be used as indicator for the quantity of phenol present in the effluent. The intensity of color developed reported [31] to be directly proportional to the quantity of phenol present in the effluent.

The results obtained using paper biosensors were analyzed in comparison with the two standard chemical methods, namely, 4-AAP and FCR assays. The values obtained by these standard assays for the similar wine, paper, and plastic industrial effluents examined (Figure 5) by the paper biosensor assay were quite comparable. A considerable difference was recorded (Figure 6) between the values recorded by paper biosensor assay and the other chemical assays. Further, the 


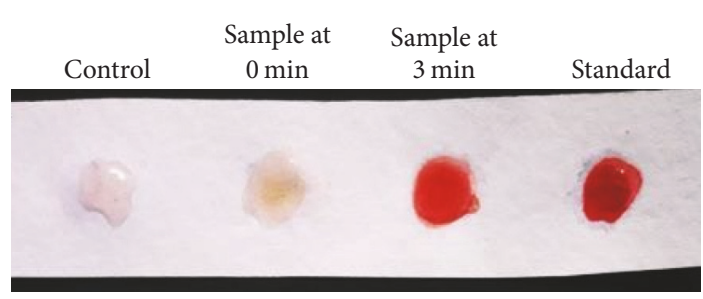

(a)

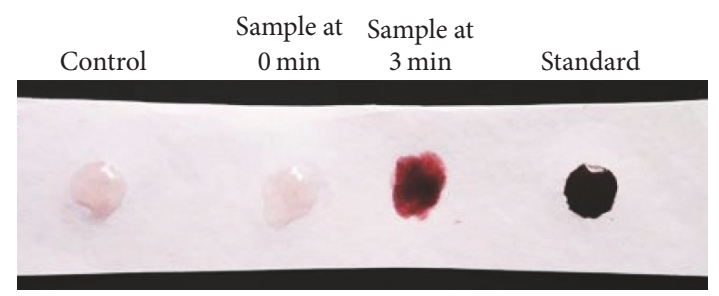

(b)

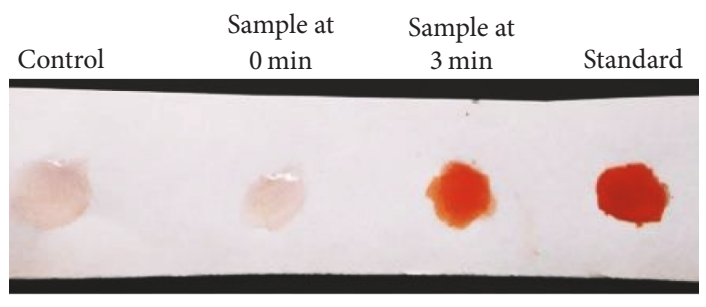

(c)

FIGURE 4: Change of color at different time intervals indicating detection of phenol from effluent of wine (a), paper (b), and plastic (c) industries by Whatman 2 paper biosensor.

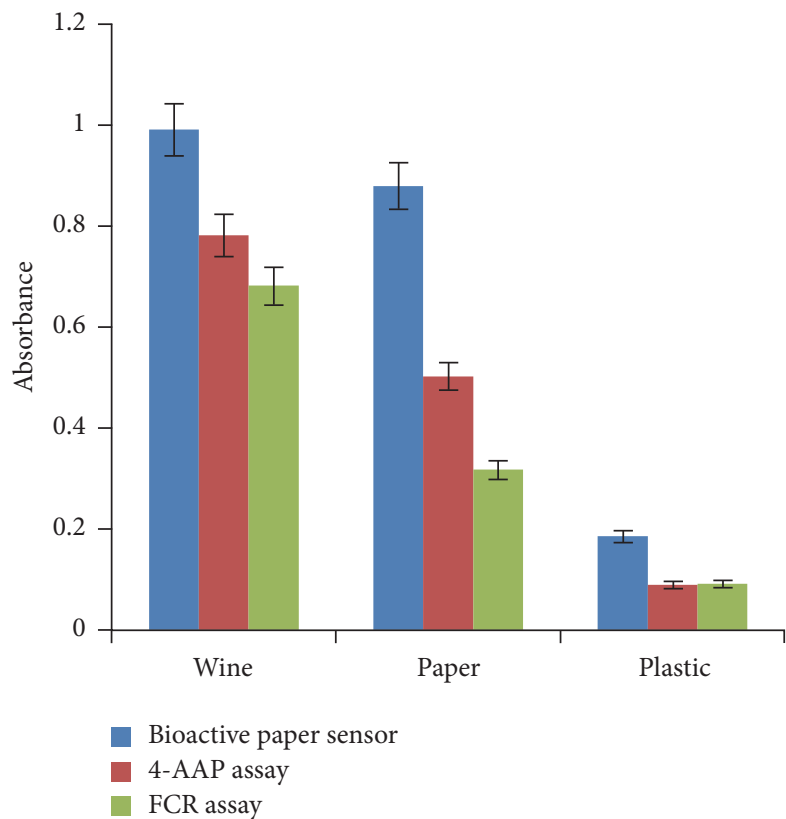

FIGURE 5: UV-vis absorption spectra indicating detection of phenol by Whatman 2 paper biosensor and standard chemical methods.

efficiency of paper biosensor in the detection of concentration of phenol was more in winery $(0.991 \mathrm{mM})$ effluent followed by paper $(0.78 \mathrm{mM})$ and plastic $(0.487 \mathrm{mM})$ industrial effluents (Figure 6).

\section{Conclusions}

Biosensors are gaining more importance over physicochemical methods in monitoring the level of analytical pollutants in the natural samples. Enzyme-nanoparticles bioconjugate

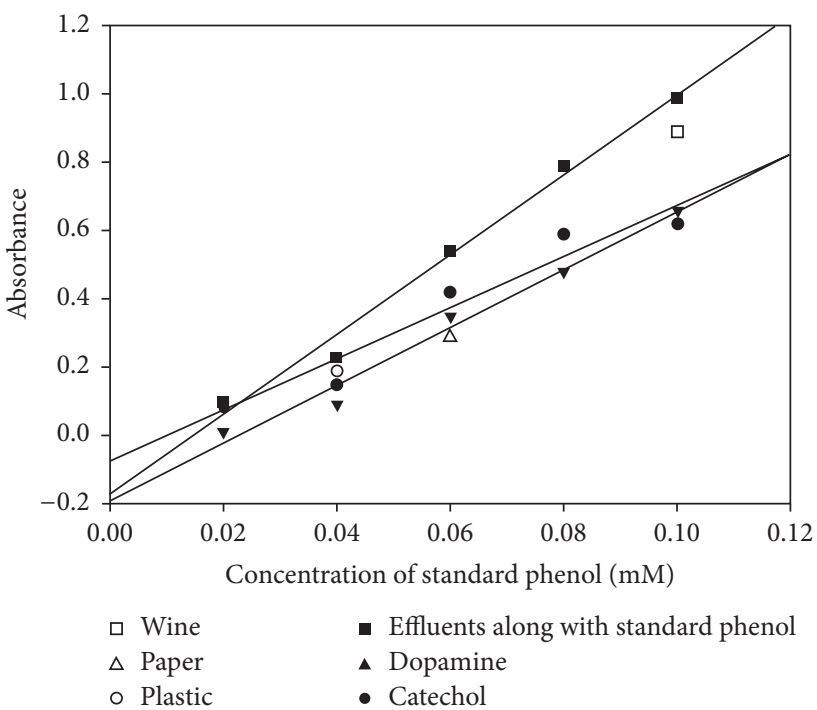

FIGURE 6: Quantitative estimation of phenol in effluent samples of wine, paper, and plastic industries by using standard phenols.

are playing vital role in the analysis of pollutants from the polluted water and soil. In the present investigation, filter paper biosensor made up of the bioconjugate of tyrosinase and gold nanoparticles was found to be very effective in the detection of phenol pollutants. Whatman number 2 filter paper biosensor could detect in $3 \mathrm{~min}$ the phenol content from the effluents of wine, paper, and plastic industries. Types and concentration of phenol contents were efficiently sensed by paper biosensor. Phenol in wine, dopamine in paper, and catechol in plastic industrial effluents were quite distinct, because of the substrate specific catalytic mechanism of tyrosinase. Gold nanoparticles persuade tyrosinase for its greater efficacy and stability in the detection of phenol 
contents, because of their Surface Plasmon Resonance. Therefore, gold nanoparticles mediated tyrosinase based paper biosensor could be a cost-effective and at ease operation for the detection of phenol pollutants from industrial effluents. A simple an efficient strip like paper biosensors can be explored for the commercial purpose on large scale.

\section{Conflicts of Interest}

The authors declare that there are no conflicts of interest regarding the publication of this paper.

\section{Acknowledgments}

The first author is grateful to Department of Science and Technology, New Delhi, India, for having granted INSPIRE Fellowship (IF-110367).

\section{References}

[1] F. Naghibi, F. Pourmorad, S. Honary, and M. Shamsi, "Decontamination of water polluted with phenol using Raphanussativus Root," Iranian Journal of Pharmaceutical Research, vol. 2, pp. 29-32, 2003.

[2] C. Hansch, S. C. McKarns, C. J. Smith, and D. J. Doolittle, "Comparative QSAR evidence for a free-radical mechanism of phenol-induced toxicity," Chemico-Biological Interactions, vol. 127, no. 1, pp. 61-72, 2000.

[3] M. Laine and N. K. Jorgense, "Straw compost and bioremediated soil as inocula for the bioremedation of chlorophenol contaminated soil," Applied and Environmental Microbiology, vol. 54, p. 1507, 1996.

[4] V. M. Daskalaki, Z. Frontistis, D. Mantzavinos, and A. Katsaounis, "Solar light-induced degradation of bisphenol-A with $\mathrm{TiO}_{2}$ immobilized on Ti," Catalysis Today, vol. 161, no. 1, pp. 110-114, 2011.

[5] K. P. Lisha, Anshup, and T. Pradeep, "Enhanced visual detection of pesticides using gold nanoparticles," Journal of Environmental Science and Health Part B: Pesticides, Food Contaminants, and Agricultural Wastes, vol. 44, no. 7, pp. 697-705, 2009.

[6] K. Ikehata and J. A. Nicell, "Color and toxicity removal following tyrosinase-catalyzed oxidation of phenols," Biotechnology Progress, vol. 16, no. 4, pp. 533-540, 2000.

[7] H. M. El-Shora and M. Metwally, "Use of tyrosinase enzyme from Bacillus thuringiensis for the decontamination of water polluted with phenols," Biotechnology, vol. 7, no. 2, pp. 305-310, 2008.

[8] E. Selinheimo, C. Gasparetti, M.-L. Mattinen, C. L. Steffensen, J. Buchert, and K. Kruus, "Comparison of substrate specificity of tyrosinases from Trichoderma reesei and Agaricus bisporus," Enzyme and Microbial Technology, vol. 44, no. 1, pp. 1-10, 2009.

[9] B. Serra, M. Dolores Morales, J. Zhang, A. J. Reviejo, E. H. Hall, and J. M. Pingarron, "In-a-day electrochemical detection of coliforms in drinking water using a tyrosinase composite biosensor," Analytical Chemistry, vol. 77, no. 24, pp. 8115-8121, 2005.

[10] D. G. Mita, A. Attanasio, F. Arduini et al., "Enzymatic determination of BPA by means of tyrosinase immobilized on different carbon carriers," Biosensors and Bioelectronics, vol. 23, no. 1, pp. 60-65, 2007.
[11] S. Chen, J. Huang, D. Du et al., "Methyl parathion hydrolase based nanocomposite biosensors for highly sensitive and selective determination of methyl parathion," Biosensors and Bioelectronics, vol. 26, no. 11, pp. 4320-4325, 2011.

[12] M. Xia, C. Chen, M. Long, C. Chen, W. Cai, and B. Zhou, "Magnetically separable mesoporous silica nanocomposite and its application in Fenton catalysis," Microporous and Mesoporous Materials, vol. 145, no. 1-3, pp. 217-223, 2011.

[13] C.-C. You, A. Verma, and V. M. Rotello, "Engineering the nanoparticle-biomacromolecule interface," Soft Matter, vol. 2, no. 3, pp. 190-204, 2006.

[14] O. Kreft, M. Prevot, H. Möhwald, and G. B. Sukhorukov, "Shellin-shell microcapsules: a novel tool for integrated, spatially confined enzymatic reactions," Angewandte Chemie-International Edition, vol. 46, no. 29, pp. 5605-5608, 2007.

[15] R. S. J. Alkasir, M. Ornatska, and S. Andreescu, "Colorimetric paper bioassay for the detection of phenolic compounds," Analytical Chemistry, vol. 84, no. 22, pp. 9729-9737, 2012.

[16] G.-Y. Kim, M.-S. Kang, J. Shim, and S.-H. Moon, "Substratebound tyrosinase electrode using gold nanoparticles anchored to pyrroloquinoline quinone for a pesticide biosensor," Sensors and Actuators, B: Chemical, vol. 133, no. 1, pp. 1-4, 2008.

[17] G.-Y. Kim, J. Shim, M.-S. Kang, and S.-H. Moon, "Preparation of a highly sensitive enzyme electrode using gold nanoparticles for measurement of pesticides at the ppt level," Journal of Environmental Monitoring, vol. 10, no. 5, pp. 632-637, 2008.

[18] G.-Y. Kim, J. Shim, M.-S. Kang, and S.-H. Moon, "Optimized coverage of gold nanoparticles at tyrosinase electrode for measurement of a pesticide in various water samples," Journal of Hazardous Materials, vol. 156, no. 1-3, pp. 141-147, 2008.

[19] J. C. Vidal, S. Esteban, J. Gil, and J. R. Castillo, "A comparative study of immobilization methods of a tyrosinase enzyme on electrodes and their application to the detection of dichlorvos organophosphorus insecticide," Talanta, vol. 68, no. 3, pp. 791799, 2006.

[20] A. Amine, H. Mohammadi, I. Bourais, and G. Palleschi, "Enzyme inhibition-based biosensors for food safety and environmental monitoring," Biosensors and Bioelectronics, vol. 21, no. 8, pp. 1405-1423, 2006.

[21] M. B. B. Zainab, D. N. Madhusudhan, H. Raghavendra, S. G. Dastager, and A. Dayanand, "Development of bioconjugate from Streptomyces tyrosinase and gold nanoparticles for rapid detection of phenol constituents," Indian Journal of Experimental Biology, vol. 52, no. 11, pp. 1071-1081, 2014.

[22] D. J. Brenner, J. T. Staley, and N. R. Krieg, "Classification of prokaryotic organisms and the concept of bacterial speciation," in Bergey's Manual of Systematic Bacteriology, D. R. Boone and R. W. Castenholz, Eds., vol. 1, pp. 27-48, Springer, Berlin, Germany, 2nd edition, 2001.

[23] A. S. Anderson and E. M. H. Wellington, "The taxonomy of Streptomyces and related genera," International Journal of Systematic and Evolutionary Microbiology, vol. 51, no. 3, pp. 797$814,2001$.

[24] X. L. Cui, P. H. Mao, M. Zeng et al., "Streptimonospora salina gen. nov., sp. nov., a new member of the family Nocardiopsaceae," International Journal of Systematic and Evolutionary Microbiology, vol. 51, no. 2, pp. 357-363, 2001.

[25] J. D. Thompson, T. J. Gibson, F. Plewniak, F. Jeanmougin, and D. G. Higgins, "The CLUSTAL_X windows interface: flexible strategies for multiple sequence alignment aided by quality analysis tools," Nucleic Acids Research, vol. 25, no. 24, pp. 48764882, 1997. 
[26] K. Lerch and L. Ettlinger, "Purification and characterization of a tyrosinase from Streptomyces glaucescens," European Journal of Biochemistry, vol. 31, no. 3, pp. 427-437, 1972.

[27] A. Ahmad, S. Senapati, M. I. Khan, R. Kumar, and M. Sastry, "Extracellular biosynthesis of monodisperse gold nanoparticles by a novel extremophilic actinomycete, Thermomonospora sp.", Langmuir, vol. 19, no. 8, pp. 3550-3553, 2003.

[28] J. D. Keighron and C. D. Keating, "Enzyme: nanoparticle bioconjugates with two sequential enzymes: stoichiometry and activity of malate dehydrogenase and citrate synthase on $\mathrm{Au}$ nanoparticles," Langmuir, vol. 26, no. 24, pp. 18992-19000, 2010.

[29] R. Pelton, "Bioactive paper provides a low-cost platform for diagnostics," TrAC-Trends in Analytical Chemistry, vol. 28, no. 8, pp. 925-942, 2009.

[30] A. J. Winder and H. Harris, "New assays for the tyrosine hydroxylase and dopa activities of tyrosinase," European Journal of Biochemistry, vol. 198, no. 2, pp. 317-326, 1991.

[31] O. Folin and W. Denis, "On phosphotungstic-phosphomolybdic compounds as colour reagents," The Journal of Biological Chemistry, vol. 12, pp. 239-243, 1912.

[32] S. Hejri and A. Saboora, "Removal of phenolic compounds from synthetic wastewaters by enzymatic treatments," JUST, vol. 35, no. 1, pp. 13-19, 2009.

[33] R. I. Amann, W. Ludwig, and K.-H. Schleifer, "Phylogenetic identification and in situ detection of individual microbial cells without cultivation," Microbiological Reviews, vol. 59, no. 1, pp. 143-169, 1995.

[34] E. Stackebrandt and B. M. Goebel, “Taxonomic note: a place for DNA-DNA reassociation and 16S rRNA sequence analysis in the present species definition in bacteriology," International Journal of Systematic Bacteriology, vol. 44, no. 4, pp. 846-849, 1994.

[35] S. A. Waksman, "Species concept among the actinomycetes with special reference to the genus Streptomyces," Bacteriological Reviews, vol. 21, no. 1, pp. 1-29, 1957.

[36] J. Kuusipalo, M. Kaunisto, A. Laine, and M. Kellomäki, "Chitosan as a coating additive in paper and paperboard," Tappi Journal, vol. 4, no. 8, pp. 17-21, 2005.

[37] P. Myllytie, J. Salmi, and J. Laine, "Effect of polymers on aggregation of cellulose fibrils and its implication on strength development in wet paper web," Nordic Pulp and Paper Research Journal, vol. 24, pp. 124-133, 2009.

[38] H. Orelma, I. Filpponen, L.-S. Johansson, J. Laine, and O. J. Rojas, "Modification of cellulose films by adsorption of cmc and chitosan for controlled attachment of biomolecules," Biomacromolecules, vol. 12, no. 12, pp. 4311-4318, 2011.

[39] N. Bordenave, S. Grelier, F. Pichavant, and V. Coma, "Water and moisture susceptibility of chitosan and paper-based materials: structure-property relationships," Journal of Agricultural and Food Chemistry, vol. 55, no. 23, pp. 9479-9488, 2007.

[40] S. C. M. Fernandes, C. S. R. Freire, A. J. D. Silvestre, J. Desbrières, A. Gandini, and C. P. Neto, "Production of coated papers with improved properties by using a water-soluble chitosan derivative," Industrial and Engineering Chemistry Research, vol. 49, no. 14, pp. 6432-6438, 2010.

[41] C. Gui, X. Dai, and D. Cui, "Advances of nanotechnology applied to biosensors," Nano Biomedicine and Engineering, vol. 3, no. 4, pp. 260-273, 2011. 

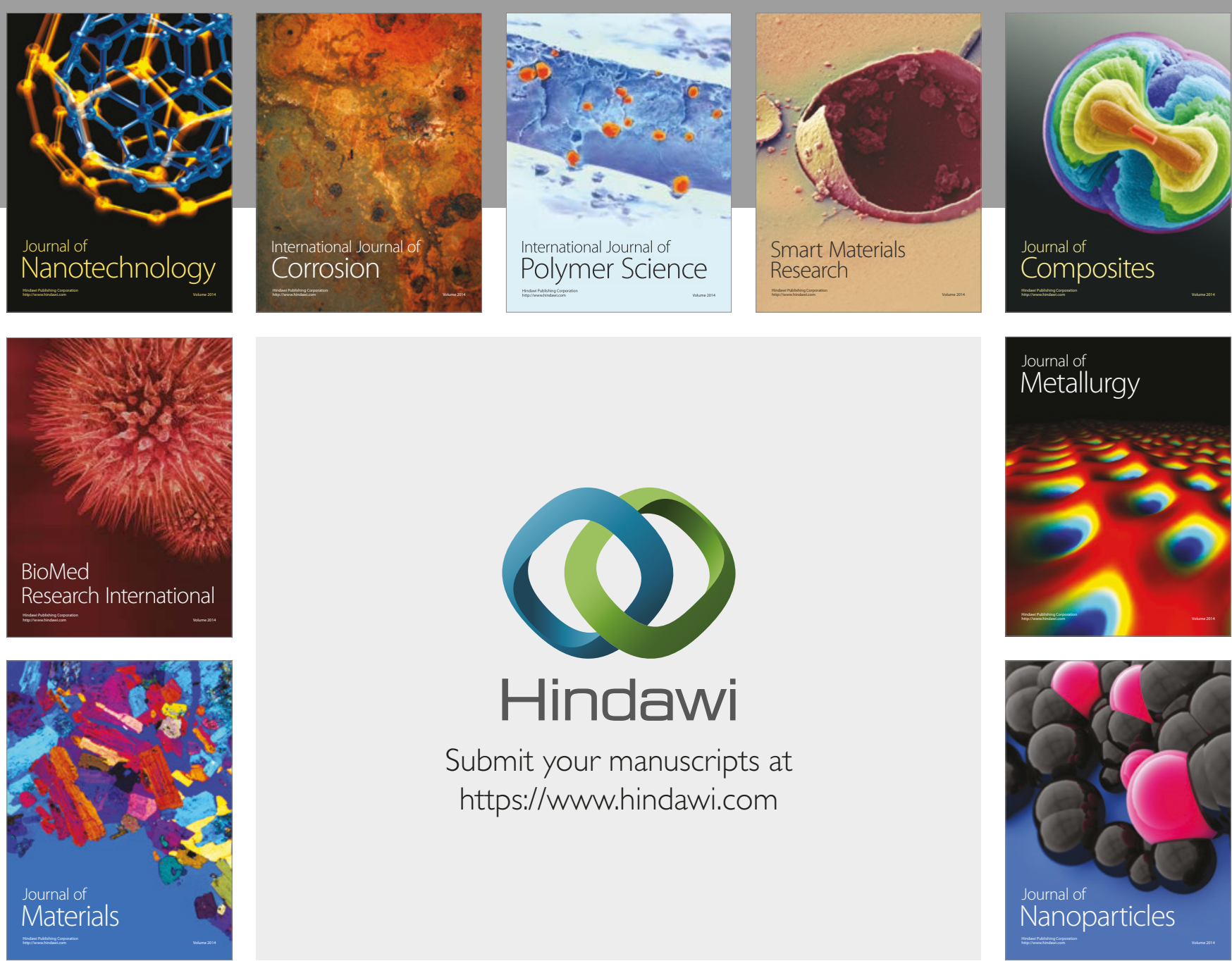

\section{Hindawi}

Submit your manuscripts at

https://www.hindawi.com
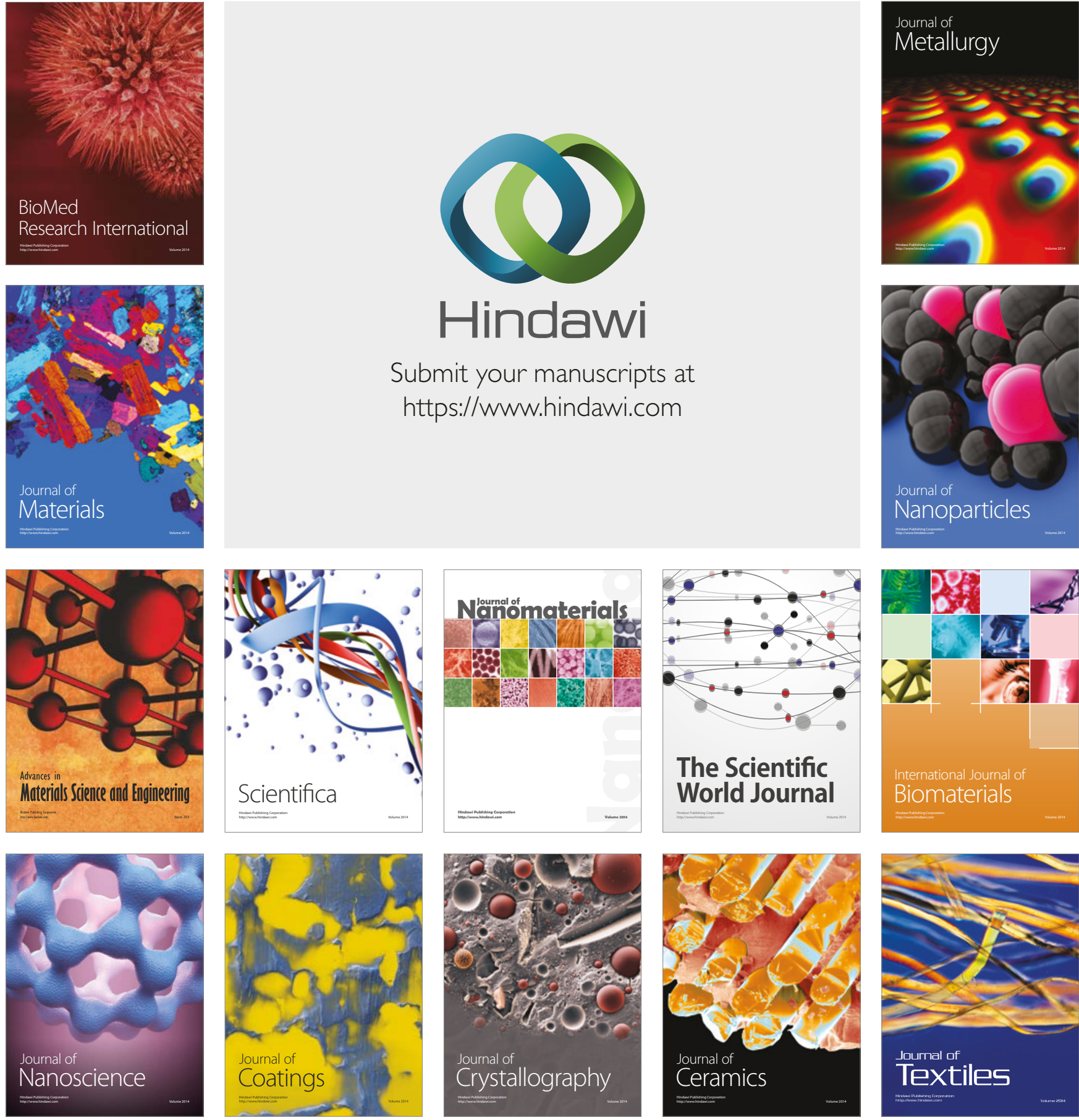

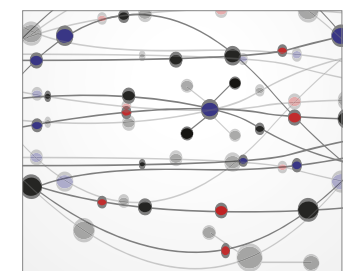

The Scientific World Journal
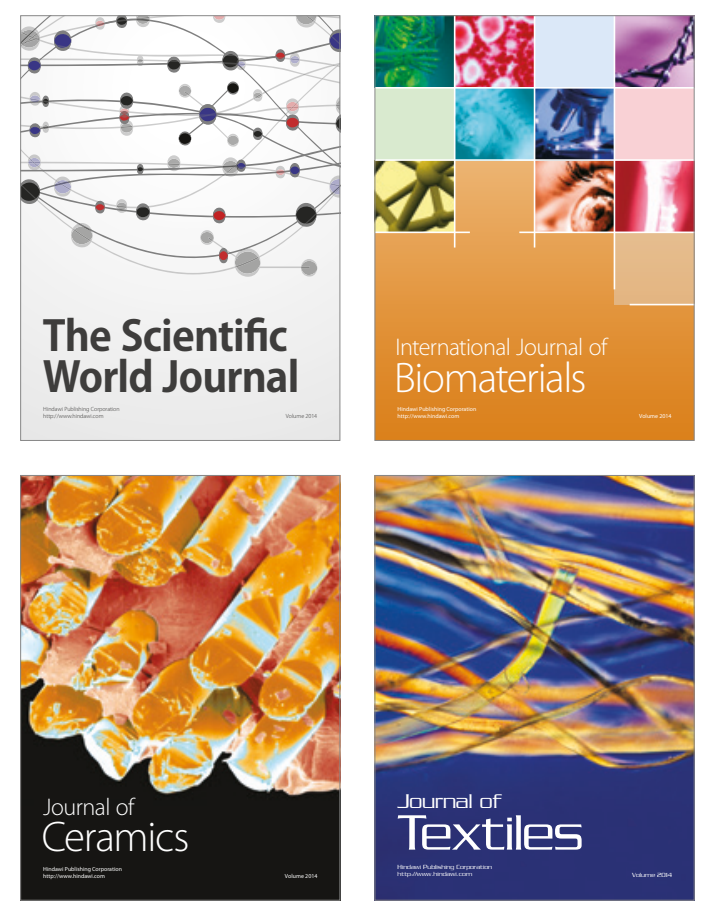